\title{
Ocular Trauma Trends in Indonesia: Poor Initial Uncorrected Visual Acuity Associated with Mechanism of Injury
}

\author{
Sauli Ari Widjaja ${ }^{1,2 *}$ (D) Yoshimune Hiratsuka $^{1}$ D, Koichi Ono $^{3}$, Ima Yustiarini $^{2} \mathbb{D}$, Nurwasis Nurwasis $^{2}$, Akira Murakami $^{1}$ (D) \\ ${ }^{1}$ Department of Ophthalmology, Graduate School of Medicine, Juntendo University, Tokyo, Japan; ${ }^{2}$ Department of \\ Ophthalmology, Faculty of Medicine, Universitas Airlangga, Dr. Soetomo General Academic Hospital, Surabaya, East Java, \\ Indonesia; ${ }^{3}$ Department of Ophthalmology, Juntendo Tokyo Koto Geriatric Medical Center, Tokyo, Japan
}

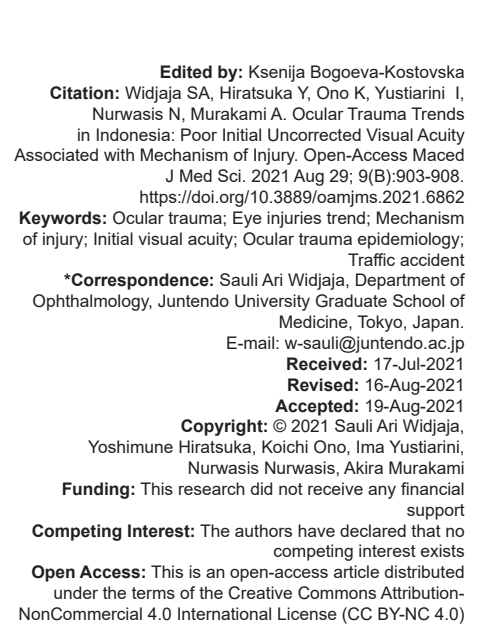

\begin{abstract}
AIM: The objectives of the study were to identify ocular trauma trends and to analyze how initial uncorrected visual acuity (VA) is associated with mechanism of injury (MOI) in a referral hospital in Indonesia.

METHODS: A 5-year medical chart reviews at the ophthalmology emergency department Dr. Soetomo Genera Academic Hospital. The information retrieved included sex, age, laterality involvement, initial uncorrected VA, MOI and management. Sex- and age-adjusted odds ratios (ORs) and $95 \%$ confidence intervals (Cls) were calculated to evaluate the relationship between poor initial uncorrected VA and $\mathrm{MOI}$, using multivariate logistic regression analysis.

RESULTS: A total of 953 patients consisted of $80.3 \%$ of males and $19.9 \%$ of females. Ocular trauma predominantly occurred in 21-30 years age group (20.9\%). May and November were found to have the highest average numbe of monthly patients. Closed globe injuries $(80.3 \%)$ were more prevalent than open globe injuries $(17.7 \%)$. The most frequent MOls were sharp objects $(311 ; 32.6 \%)$, followed by blunt objects $(236 ; 24.8 \%)$. Most cases $(89.2 \%)$ displayed unilateral involvement and $54.3 \%$ of cases showed an initial uncorrected VA of better than $6 / 18$. Compared to road dust, blunt object, sharp object, and traffic accident were significantly associated with poor initial VA, with adjusted ORs (95\% Cls) of 5.24 (2.27-12.10), 4.03 (1.76-9.25), and 8.17 (3.31-20.15), respectively.
\end{abstract}

CONCLUSION: Initial uncorrected VA and MOI provide earlier information regarding the prognosis. Traffic accident showed a greater tendency to cause a poor initial uncorrected VA. Most ocular trauma is preventable by educating people at risk to avoid common MOls and to use protection.

\section{Introduction}

Injuries are a common health problem in Southeast Asia Region [1]. Approximately 1.6 million people are left blind due to ocular trauma, 2.3 million people experience low vision bilaterally and 19 million suffer from a loss of unilateral vision [2]. In the emergency department (ED), orbital trauma is one of the most common reasons for referral to an ophthalmologist [3]. In Singapore, every 1 in 20 people experience eye injury [4]. Based on a Basic Health Research in 34 provinces conducted by the Ministry of Health in Indonesia, namely, Riset Kesehatan Dasar (Riskesdas) in 2018, eye injury is included in the six most common types of trauma. According to Basic Health Research in 2018, of all the types of injuries, including concussions, internal organ injuries, and burns, the incidence of ocular trauma in Indonesia was estimated to be 46,488 cases per year, which in East Java is estimated to be 8236 cases per year [5].

Ocular trauma trends vary geographically and internationally due to differences in lifestyle, society, work, culture, and legislation. Epidemiological data on eye trauma have been described in many countries; however, these data are limited in Southeast Asia as, especially in Indonesia, one of the developing countries in the region, the incidence of ocular trauma is underreported and not many studies related to ocular trauma epidemiology have been undertaken. Therefore, we retrospectively investigated demographic characteristic, clinical features, severity, initial uncorrected visual acuity (VA), mechanism of injury (MOI), and management of ocular trauma in Dr. Soetomo General Academic Hospital (DSGAH) as 1 of the 14 hospitals designated as a national referral hospital in East Java, Indonesia.

This study was conducted to provide an epidemiological profile and trends of ocular trauma in a tertiary care hospital, and to verify whether ocular trauma occurs more frequently in specific months or during specific seasons so that preventive measures can be precisely determined. Resulting ocular injuries will underline the value of tracking the impact of current regulations on ocular injuries rates. Initial VA found to be significant factor for final 
VA outcome [6], [7], [8], [9]. Therefore, knowing the distribution of $\mathrm{MOI}$ and its association with initial VA will help in the planning of treatment strategies and campaigns for preventing those $\mathrm{MOI}$ using safety equipment and raising public awareness not only limited to people at risk of trauma, especially during the periods in which ocular trauma tends to occur. This study can also provide some references to future researchers who want to further research on ocular trauma in this part of the country, especially in the era of a better health referral system.

\section{Methods}

As an Indonesian national referral hospital, DSGAH experienced a wide variety of cases concerned with ocular emergencies referred to this hospital. Patients seen in the Ophthalmology ED (OED) of DSGAH, available $24 \mathrm{~h}$ a day, were first managed by ophthalmology residents and ophthalmologist consultant in charge. In the ED setting, the resident took the patients' history and performs uncorrected VA examination followed by thorough ocular examination and management. All data documented in the emergency note case and medical record were reviewed retrospectively.

This study obtained approval from the DSGAH Institutional Review Board. In agreement with the tenets of the Declaration of Helsinki, a retrospective emergency note case and medical chart review of patients presented to the OED between January 2014 and December 2018 were collected. From this, data related to sex, age, laterality involvement, initial uncorrected VA, MOI, diagnosis, and management were retrieved.

Age classification was divided into 10 groups with a range of 10 years each group. Initial uncorrected VA gained with Snellen charts and was converted to LogMAR for analysis. The eye with the worst uncorrected VA would be selected in case of bilateral involvement. Initial uncorrected VA was then classified into three groups, VA 6/6-6/18, less than 6/18-3/60, and less than $3 / 60$ - no light perception (NLP), to know the number of patients with severe initial visual impairment. Then, initial uncorrected VA was distributed according to $\mathrm{MOI}$. Further, we analyzed which group of $\mathrm{MOI}$ showed poor or better initial uncorrected VA.

In our study, laterality was defined as only one side or both sides of the eye being affected. We briefly divided diagnosis into two broad categories, open globe injury (OGI) and closed globe injury (CGI), according to the Birmingham Eye Trauma Terminology System [10], where the eyewall is defined as the cornea and sclera. CGI was defined as no full-thickness wound of the eyewall, while OGI was defined as a full-thickness wound of the eyewall. MOl was divided into blunt object (impact from any blunt object without any sharp edge), sharp object, chemicals, traffic accident, light injury, road dust, and others that include electrical, insect bite, contact lens related, tree latex, cigarette ash, flame or firework, and thermal injury. Management of the patient was defined as whether the patient had conservative medical or surgical intervention.

Descriptive statistics were reported as mean and standard deviations (SD) for continuous variables and as numbers and percentages for categorical variables. Crude and adjusted odds ratios (ORs) and $95 \%$ confidence intervals $(95 \% \mathrm{Cls}$ ) were calculated to understand the association between poor initial uncorrected VA $(\mathrm{VA}<3 / 60-\mathrm{NLP})$ and $\mathrm{MOI}$ using simple or multivariate logistic regression analysis. In the analysis, road dust, which was considered to be the mildest trauma among the $\mathrm{MOI}$, was set as the reference group. We set the level of statistical significance at $p<0.05$ for a two-sided test. All statistical analyses were performed using IBM SPSS 23 and Stata 15 (StataCorp, College Station, TX, USA).

\section{Results}

Over the 5-year period, 953 patients were diagnosed with ocular trauma, with an average annual number of 190 patients. When broken down monthly each year, there were two highest clusters of cases; the first cluster was between March and May and the second was between October and November (Figure 1). The average monthly over 5 years was 15.9 patients. Moreover, May and November were found to have the highest mean monthly number of patients, as presented in Figure 2.

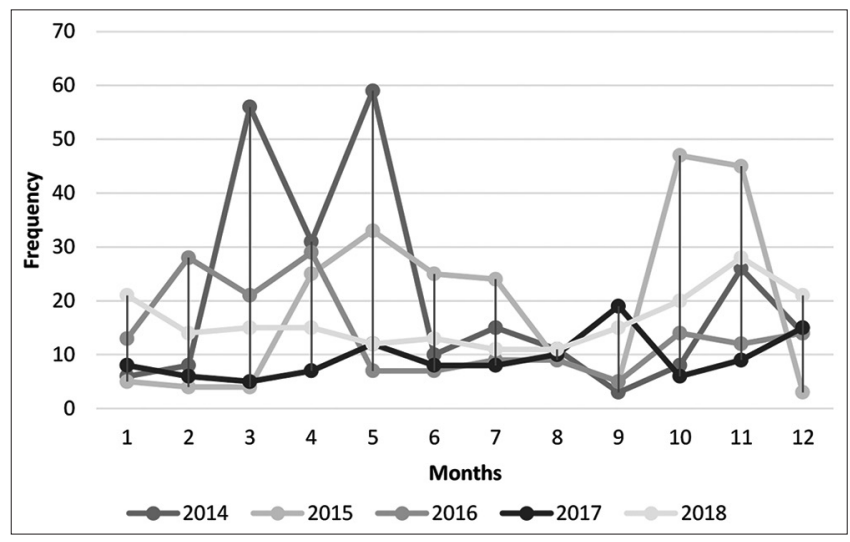

Figure 1: This figure shows the total number of patients monthly each year. There were two highest clusters months, between March and May and the second cluster months between October and November

In terms of gender, the incidence of ocular trauma was found to be higher in males than in females, with $763(80.1 \%)$ males and 190 (19.9\%) females being referred (Table 1), while their age ranged from 0.5 to 84 years (mean $\pm S D=34.7 \pm 17.7$ years) 


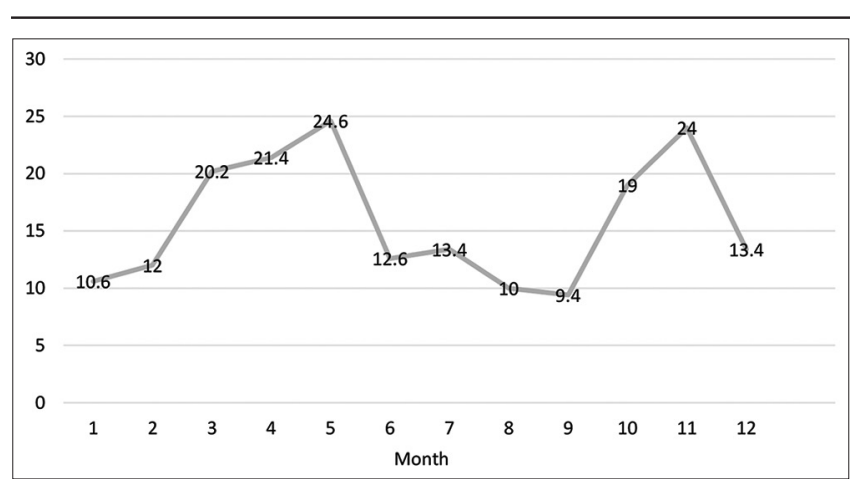

Figure 2: This figure shows the average number of patients monthly in 5 years. The average number monthly was 15.9 patients while May and November were found to have the highest mean monthly number of patients

The distribution of ocular trauma was most frequent in the middle age group of 21-50 years, with the highest proportion in the $21-30$ years old group (20.9\%), depicted in Table 1. There were 850 cases $(89.2 \%)$ of unilateral involvement and $102(10.7 \%)$ cases of bilateral involvement, in which $667(70.2 \%)$ patients received medical intervention and $194(20.4 \%)$ received surgical intervention. This study found $765(80.3 \%)$ CGIs and $169(17.7 \%)$ OGls. The most frequent MOI were sharp objects $(311 ; 32.6 \%)$, followed by blunt objects $(236(24.8 \%)$, traffic accidents $(101 ; 10.6 \%)$, chemical trauma $(96 ; 10.1 \%)$, and road dust $(87 ; 9.1 \%)$. Over the 5-year period, it appeared that sharp object and blunt object occupied the two highest positions (Table 2).

Table 1: Demographic characteristics of ocular trauma patients

\begin{tabular}{llll}
\hline Characteristic & Male $(\mathrm{n})$ & Female $(\mathrm{n})$ & Total $(\mathrm{n}, \%)$ \\
\hline Age groups & & & \\
$0-10$ & 64 & 20 & $84(8.8)$ \\
$11-20$ & 80 & 25 & $105(11)$ \\
$21-30$ & 158 & 41 & $199(20.9)$ \\
$31-40$ & 149 & 24 & $173(18.2)$ \\
$41-50$ & 118 & 21 & $139(14.6)$ \\
$51-60$ & 77 & 26 & $103(10.8)$ \\
$61-70$ & 40 & 12 & $52(5.5)$ \\
$71-80$ & 13 & 5 & $18(1.9)$ \\
$81-90$ & 2 & 2 & $4(0.4)$ \\
Unknown & 62 & 14 & $76(7.9)$ \\
Total & $763(80.1 \%)$ & $190(19.9 \%)$ & $953(100)$ \\
\hline
\end{tabular}

The mean initial uncorrected VA at the time of presentation showed LogMAR $0.93 \pm 0.96$ (range $0.0-3.0)$. Table 2 shows that the majority $(39.5 \%)$ had an initial uncorrected VA of better than 6/18 (LogMAR $0.5), 25.4 \%$ had an initial uncorrected VA between less than $6 / 18$ and $3 / 60$ (less than LogMAR 0.5 to 1.3), and the remaining $23.8 \%$ had an initial uncorrected VA of less than $3 / 60$ to NLP (greater than LogMAR 1.3). In the sharp object group, the largest proportion was good

Table 2: Frequency of initial uncorrected visual acuity according to the mechanism of injury

\begin{tabular}{|c|c|c|c|c|c|}
\hline \multirow{2}{*}{$\begin{array}{l}\text { Mechanism of } \\
\text { injury }\end{array}$} & \multicolumn{4}{|c|}{ Frequency of initial uncorrected visual acuity } & \multirow[t]{2}{*}{ Total (\%) } \\
\hline & $\begin{array}{l}\text { 6/6-6/18 } \\
(\%)\end{array}$ & $\begin{array}{l}<6 / 18- \\
3 / 60(\%)\end{array}$ & $\begin{array}{l}<3 / 60-\text { no light } \\
\text { perception }(\%)\end{array}$ & $\begin{array}{l}\text { Unknown } \\
(\%)\end{array}$ & \\
\hline Blunt object & $76(32.2)$ & $60(25.4)$ & $75(31.8)$ & $25(10.6)$ & $236(100)$ \\
\hline Sharp object & $149(47.9)$ & $51(16.4)$ & $78(25.1)$ & $33(10.6)$ & $311(100)$ \\
\hline Chemical & $40(41.7)$ & $34(35.4)$ & 13 (13.5) & $9(9.4)$ & $96(100)$ \\
\hline Traffic accident & $20(19.8)$ & $30(29.7)$ & $37(36.6)$ & $14(13.9)$ & $101(100)$ \\
\hline Light injury & $10(47.6)$ & $8(38.1)$ & $1(4.8)$ & $2(9.5)$ & $21(100)$ \\
\hline Road dust & $48(55.2)$ & $22(25.3)$ & $7(8.1)$ & $10(11.4)$ & $87(100)$ \\
\hline Others & $27(42.8)$ & $22(34.9)$ & $12(19.1)$ & $2(3.2)$ & $63(100)$ \\
\hline Unknown & $6(15.8)$ & 15 (39.5) & $4(10.5)$ & $13(34.2)$ & $38(100)$ \\
\hline Total & $376(39.5)$ & $242(25.4)$ & $227(23.8)$ & $108(11.3)$ & $953(100)$ \\
\hline
\end{tabular}

initial uncorrected VA at $47.9 \%$, meanwhile in the traffic accident group, the highest proportion was poor initial uncorrected VA $(<3 / 60-N L P)$ at $36.6 \%$. Table 3 shows the association between $\mathrm{MOI}$ and poor initial uncorrected VA (crude and adjusted ORs and Cls). Compared to road dust, blunt object, sharp object, and traffic accident were significantly associated with poor initial uncorrected VA with adjusted ORs (95\% Cls) of 5.24 (2.27-12.10), 4.03 (1.76-9.25), and 8.17 (3.3120.15), respectively.

Table 3: Association between poor initial uncorrected visual acuity and mechanism of injury

\begin{tabular}{lllllll}
\hline $\begin{array}{l}\text { Mechanism of } \\
\text { injury }\end{array}$ & $\begin{array}{l}\text { Crude } \\
\text { odds ratio }\end{array}$ & $\begin{array}{l}95 \% \\
\text { confidence } \\
\text { interval }\end{array}$ & $\begin{array}{l}\text { p-value } \\
\text { Bdjusted } \\
\text { odds } \\
\text { ratio }\end{array}$ & $\begin{array}{l}95 \% \\
\text { confidence } \\
\text { interval }\end{array}$ & -value \\
\hline Blunt object & 5.51 & $2.41-12.60$ & 0.00 & 5.24 & $2.27-12.10$ & $<0.01$ \\
Sharp object & 3.9 & $1.72-8.85$ & 0.00 & 4.03 & $1.76-9.25$ & $<0.01$ \\
Chemical & 1.76 & $0.66-4.66$ & 0.26 & 1.92 & $0.72-5.12$ & 0.20 \\
Traffic accident & 7.4 & $3.05-17.94$ & 0.00 & 8.17 & $3.31-20.15$ & $<0.01$ \\
Light injury & 0.56 & $0.06-4.81$ & 0.59 & 0.60 & $0.07-5.20$ & 0.64 \\
Others & 2.45 & $0.90-6.66$ & 0.08 & 2.58 & $0.94-7.07$ & 0.07 \\
\hline
\end{tabular}

\section{Discussion}

In this medical chart review study, we observed that May and November showed the highest incident of cases, presumably due to seasonal variation. Further, initial VA is closely correlated with final VA prognosis [6], [7], [8], [9]. As for MOI, blunt object, sharp object, and traffic accident were significantly associated with worse initial uncorrected VA. This study revealed that blunt object increases the risk of poor initial VA compared to sharp objects, which means an increased prognosis for worse final VA outcomes. Traffic accident showed an 8 times greater tendency to cause a poor initial VA when compared to road dust. Thus, ocular trauma related to traffic accidents is a leading yet preventable cause of visual impairment and is of concern to public health [11].

In this study, in the sharp object group, the largest proportion was found with good initial uncorrected VA. This may be due to the sharp object not hitting the globe, resulting in only palpebral or adnexal lacerations, a condition that was classified as CGI in this study. This is in line with other studies regarding sharp objects having better final VA as compared to blunt trauma. When compared to OGI, visual prognosis of $\mathrm{CGI}$ appeared to have a better prognosis [8], [12]. This study was in agreement with the results of several other studies in terms of variations in total number of patients per year [13], seasonal variation that is influenced by different moon peaks and clusters in certain months [13], [14], higher male preponderance [6], [7], [15], [16], [17], [18], [19], predominant occurrence in productive ages [9], [20], [21], and unilaterality [16], [22], [23]. Another study reported that the most common causes of decrease in vision were penetrating injuries and intraocular foreign bodies 
(IOFBs) [24]. Whereas, in terms of CGI, our result was inconsistent with studies conducted in China and Iran [8], [15], [25]. Further, many studies reported that mostof the cases required surgical treatment[6],[15], [23], [26], had more than 1 surgery [19] and additional procedures [12]. The type of treatment thus depends on the severity and characteristic of the eye trauma. Meanwhile, some other studies reported that commonly MOls were splashing of IOFBs [18], [22], traffic accidents [17], [27], explosives materials [18], firework related [25], chemical injuries [28], and caused during sports or recreational activities [26].

The prevailing trend of ocular trauma each year is different in each country. From the study in the USA by Ramirez et al., the average number of eye trauma visits decreased by $4 \%$ every year during the study period, with the same pattern of decline each month, showing a statistically significant annual cycle with an average annual peak between May and July [13]. Furthermore, seasonal variations correspond to the conditions in each country; for example, they can be related to the harvest season of agriculture [29] or can be seen to increase in non-winter months [13], [30]. Indonesia has a tropical climate with two seasons and when, from November to May, rainfall is high. The increasing number of motor vehicles in Indonesia, especially in Java Island, as a mode of land transportation also raises the rate of traffic accidents every year [31]. As such, weather is an external factor that has a substantial influence on driving behavior, which increases the likelihood of a traffic accident [32], [33] as well as the impaired road conditions mentioned by other studies in Indonesia [34], [35]. Variations and changes in trauma trends are also influenced by active or passive leisure activities [36]. A higher male preponderance is multifactorial that includes aggressive behavior, being involved in fights [7], [12], [29], participation in dangerous sports [37], engaging in more physical work and higher risk of eye trauma [6], [12], [18], alcohol and drug abuse [7], no device protection at work [7], or driving carelessly [15]. In Indonesia, most females are housewives and engaged in occupations or physical work with low risk of eye trauma. As such, trauma incidence in the productive age is predominant because people of this age group engage more in physical work [18] and are at a higher risk of work-related, sports-related, or traffic accidentrelated injuries [38]. In Indonesia, this is also related to the lack of knowledge about the prevention of eye trauma, as mentioned in a study by Alem et al. in Ethiopia [39]. Alem et al. found that nearly two-thirds (62.87\%) of patients with ocular trauma were children followed by teenagers $(20.67 \%)$ and the variations might be due to lack of knowledge-related accidents. The majority of ocular trauma patients $(74.51 \%)$ presented to Hawassa University tertiary eye care facility 3 days after their injuries, and only $1.29 \%$ of the total patients were treated within $6 \mathrm{~h}$. The disparities in presentation time might be attributed to trauma awareness, distance from eye care centers, poverty, and transportation system [39].
The difference of the incidence and the causes of ocular trauma between countries might be due to socioeconomic, knowledge, awareness, or cultural conditions. This study provides useful information on the incidence and patterns of ocular trauma in one referral hospital in Indonesia. Ocular trauma patients can be informed earlier once initial VAand MOI have been revealed regarding the prognosis and pending further prevention of sharp object, blunt object, or traffic accident-related trauma. Moreover, this study can serve as a reference to future researchers working on ocular trauma epidemiology as there are very limited published data concerning this field in Indonesia. Even though the period of data retrieval in this study was a period where the implementation of a better health referral system in Indonesia was still ongoing, it appeared that not only trauma cases that required complex treatment but also mild cases that ought to be handled at a lower level of complexity were referred to this center. Further prospective research should be conducted in the era of improvement of the health referral system for comparison. A future multicenter study or prospective nationwide level to identify the risk factor and more detail review for eye injury presenting to the ED will also be of benefit.

Our study has several limitations, including review procedures that were conducted retrospectively and limited to data available at the time of presentation. There were no detailed data on the level of education, employment, and history of eye trauma, including whether the patient was using protective equipment or not. Initial VA assessment at the ED was done uncorrected and may have resulted in bias in determining whether the decrease in VA was mainly due to eye trauma or another cause. Due to the lack of available data, we did not classify the diagnosis in more detail. Some patients with multiple traumas who were admitted in other departments may not have been reviewed in this study either. Furthermore, seasonal variation has not been analyzed in detail. In addition, this study came from a single center and only analyzed cases at the ED, whereas other regions of Indonesia are very likely to have different patterns.

\section{Conclusion}

In summary, blunt object, sharp object, and traffic accident-related trauma were significantly associated with worse initial uncorrected VA. Moreover, traffic accident showed a greater tendency to cause a poor initial uncorrected VA. MOI and initial uncorrected VA provide firsthand information regarding the prognosis of ocular trauma patients. Finally, many ocular traumas are preventable by educating people at risk to increase awareness, avoid common MOls, and use protection to reduce the incidence and severity of ocular trauma, especially in certain months when ocular trauma tends to occur more frequently. 


\section{Acknowledgments}

The authors would like to thank ocular trauma team and residents in charge in Ophthalmology Emergency Department Dr. Soetomo General Academic Hospital, dr. Ratna Doemilah, SpM(K), dr. Sutjipto, $\operatorname{SpM}(\mathrm{K})$, dr. Ifan Romadhon Lukmana, SpM, dr. Christi Ervina H, dr. Amelia Rahmah Kartika and Siti Rukayah, for their contribution to this study.

\section{References}

1. Dhillon PK, Jeemon P, Arora NK, Mathur P, Maskey M, Sukirna RD, et al. Status of epidemiology in the WHO SouthEast Asia region: Burden of disease, determinants of health and epidemiological research, workforce and training capacity. Int J Epidemiol. 2012;41(3):847-60. https://doi.org/10.1093/ije/ dys046

PMid:22617689

2. Négrel A, Thylefors B. The global impact of eye injuries. Ophthalmic Epidemiol. 1998;5(3):143-69. https://doi. org/10.1076/opep.5.3.143.8364

PMid:9805347

3. Lin KY, Ngai P, Echegoyen JC, Tao JP. Imaging in orbital trauma. Saudi J Ophthalmol. 2012;26(4):427-32.

PMid:23961028

4. Chua D, Wong W, Lamoureux EL, Aung T, Saw SM, Wong TY. The prevalence and risk factors of ocular trauma: The Singapore Indian eye study. Ophthalmic Epidemiol. 2011;18(6):281-7. https://doi.org/10.3109/09286586.2011.628775

PMid:22053838

5. Kementerian Kesehatan RI. Laporan Riskesdas 2018. Lap Nas Riskesdas. Vol. 53. Indonesia: Kementerian Kesehatan Rl; 2018. p. 181-222. Available from: http://www.yankes.kemkes. go.id/assets/downloads/pmk no.57tahun2013tentangptrm.pdf. [Last accessed on 2021 Jan 25].

6. Zhang $X$, Liu $Y$, Ji X, Zou Y. A retrospective study on clinical features and visual outcome of patients hospitalized for ocular trauma in Cangzhou, China. J Ophthalmol. 2017;2017:7694913. https://doi.org/10.1155/2017/7694913

PMid:28386477

7. Mallika PS, Tan AK, Asok T, Faisal HA, Aziz S, Intan G. Pattern of ocular trauma in Kuching, Malaysia. Malays Fam Physician. 2008;3(3):140-5.

PMid:25606139

8. Wang W, Zhou Y, Zeng J, Shi M, Chen B. Epidemiology and clinical characteristics of patients hospitalized for ocular trauma in South-Central China. Acta Ophthalmol. 2017;95(6):e503-10. https://doi.org/10.1111/aos.13438

PMid:28371405

9. Meng Y, Yan H. Prognostic factors for open globe injuries and correlation of ocular trauma score in Tianjin, China. J Ophthalmol. 2015;2015:345764. https://doi.org/10.1155/2015/345764 PMid:26491549

10. Kuhn F, Morris R, Mester V, Witherspoon CD. Terminology of mechanical injuries: The Birmingham eye trauma terminology (BETT). In: Ocular Traumatology. Berlin, Germany: Springer; 2008. p. 3-11. https://doi.org/10.1007/978-3-540-33825-3_1

11. Puzari BS, Das RK, Pegu I. A study on ocular injuries following road traffic accidents. Int J Res Med Sci. 2017;5(2):627. https:// doi.org/10.18203/2320-6012.ijrms20170164

12. Cao H, Li L, Zhang M. Epidemiology of patients hospitalized for ocular trauma in the Chaoshan region of China, 2001-2010. PLoS One. 2012;7(10):e48377. https://doi.org/10.1371/journal. pone.0048377

PMid:23118997

13. Ramirez DA, Porco TC, Lietman TM, Keenan JD. Ocular injury in United States emergency departments: Seasonality and annual trends estimated from a nationally representative dataset. Am J Ophthalmol. 2018;191(1):149-55. https://doi.org/10.1016/j. ajo.2018.04.020 PMid:29750945

14. Kwon JW, Choi MY, Bae JM. Incidence and seasonality of major ocular trauma: A nationwide population-based study. Sci Rep. 2020;10(1):10020. https://doi.org/10.1038/ s41598-020-67315-9

PMid:32572124

15. Movahedinejad T, Adib-Hajbaghery M, Zahedi MR. A study on hospital admissions for eye trauma in Kashan, Iran. Trauma Mon. 2016;21(2):e28073. https://doi.org/10.5812/traumamon.28073 PMid:27626013

16. Toride A, Toshida H, Matsui A, Matsuzaki Y, Honda R, Ohta T, et al. Visual outcome after emergency surgery for open globe eye injury in Japan. Clin Ophthalmol. 2016;10:1731-6. https:// doi.org/10.2147/opth.s103704 PMid:27660410

17. Patil S, Biala A, Khanna A, Meena A. Prevalence of ocular trauma in KLES hospital: A 1-year cross-sectional study. Indian J Health Sci. 2016;9(2):175-8. Available from: https://www. ijournalhs.org/text.asp?2016/9/2/175/191262. [Last accessed on 2019 Jun 15]. https://doi.org/10.4103/2349-5006.191262

18. Li L, Lu H, Ma K, Li YY, Wang HY, Liu NP. Etiologic causes and epidemiological characteristics of patients with intraocular foreign bodies: Retrospective analysis of 1340 cases over ten years. J Ophthalmol. 2018;2018:6309638. PMid:29651344

19. Agrawal R, Wei HS, Teoh S. Prognostic factors for open globe injuries and correlation of ocular trauma score at a tertiary referral eye care Centre in Singapore. Indian J Ophthalmol. 2013;61(9):502-6. https://doi.org/10.4103/0301-4738.119436 PMid:24104709

20. Lubis RR, Limanto $V$, Putri R, Lubis AN, Arrasyid NK Epidemiological characteristics of work-related ocular trauma among the carpenters in Medan, Indonesia. Open Access Maced J Med Sci. 2018;6(11):2119-22. https://doi.org/10.3889/ oamjms.2018.441 PMid:30559872

21. Pandita A, Merriman M. Ocular trauma epidemiology: 10-year retrospective study. N Z Med J. 2012;125(1348):61-9. PMid:22282278

22. Voon LW, See J, Wong TY. The epidemiology of ocular trauma in Singapore: Perspective from the emergency service of a large tertiary hospital. Eye (Lond). 2001;15(1):75-81. https://doi. org/10.1038/eye.2001.18

PMid:11318302

23. Makhrash MA, Gosadi IM. Open globe eye injury characteristics and prognostic factors in Jazan, Saudi Arabia. Saudi Med J. 2016;37(12):1328-33. https://doi.org/10.15537/ smj.2016.12.15545

PMid:27874147

24. Oum BS, Lee JS, Han YS. Clinical features of ocular trauma in emergency department. Korean J Ophthalmol. 2004;18(1):70-8. https://doi.org/10.3341/kjo.2004.18.1.70 
PMid:15255241

25. Qi Y, Zhang FY, Peng GH, Zhu Y, Wan GM, Wang WZ, et al Characteristics and visual outcomes of patients hospitalized for ocular trauma in Central China: 2006-2011. Int J Ophthalmol. 2015;8(1):162-8.

PMid:25709927

26. Mishra A, Parihar J, Verma A, Aggarwal S, Baranwal V, Bhargava $\mathrm{N}$. The pattern and visual outcomes of ocular trauma in a large zonal hospital in a non-operational role: A 36 months retrospective analysis. J Clin Ophthalmol Res. 2014;2(3):141-4. Available from: https://www.jcor.in/text. asp?2014/2/3/141/138856. [Last accessed on 2019 Jun 15]. https://doi.org/10.4103/2320-3897.138856

27. Pai SG, Kamath SJ, D'Souza S, Dudeja L. A clinical study of blunt ocular trauma in a tertiary care centre. Online J Health Allied Sci. 2013;12(2):2-5.

28. Monsudi K, Adekoya B, Grace A. Bilateral blindness from ocular injury: A 15 year review. Afr J Trauma. 2014;3(1):358. Available from: https://www.afrjtrauma.com/text asp?2014/3/1/35/139467. [Last accessed on 2019 Jun 15]. https://doi.org/10.4103/1597-1112.139467

29. Okeigbemen V, Osaguona V. Seasonal variation in ocular injury in a tertiary health center in Benin city. Sahel Med J. 2013;16(1):10-4. Available from: https://www.smjonline.org/text. asp?2013/16/1/10/112055. [Last accessed on 2019 Jun 15]. https://doi.org/10.4103/1118-8561.112055

30. Dryden SC, Jensen JD, Fleming JC, Fowler BT. Ocular trauma: Trends and considerations for resident education. J Acad Ophthalmol. 2020;12(1):e46-51. https://doi. org/10.1055/s-0040-1709177

31. Mahendradhata $Y$, Trisnantoro $L$, Listyadewi $S$, Soewondo $P$, Marthias T, Harimurti P, et al. The Republic of Indonesia Health System Review. WHO Regional Office for South-East Asia. Vol. 7. Geneva: World Health Organization; 2017. Available from: https://www.apps.who.int/iris/handle/10665/254716.
[Last accessed on 2021 Mar 30].

32. Cai X, Lu JJ, Xing Y, Jiang C, Lu W. Analyzing driving risks of roadway traffic under adverse weather conditions: In case of rain day. Procedia Soc Behav Sci. 2013;96:2563-71. https://doi. org/10.1016/j.sbspro.2013.08.287

33. Chakrabarty N, Gupta K. Analysis of driver behaviour and crash characteristics during adverse weather conditions. Procedia Soc Behav Sci. 2013;104:1048-57. https://doi.org/10.1016/j. sbspro.2013.11.200

34. Siregar ML, Jachrizal Sumabrata R, Kusuma A, Samosir OB, Rudrokasworo SN. Analyzing driving environment factors in pedestrian crashes injury levels in Jakarta and the surrounding cities. J Appl Eng Sci. 2019;17(4):482-9. https://doi.org/10.5937/ jaes17-22121

35. Ismaili AF. The influence of weather on the behavior of motorcycle riders in the special area of Yogyakarta. Semesta Tek. 2017;20(2):132-8.

36. McGwin G, Hall TA, Xie A, Owsley C. Trends in eye injury in the United States, 1992-2001. Invest Ophthalmol Vis Sci. 2006;47(2):521-7. https://doi.org/10.1167/iovs.05-0909 PMid:16431945

37. Iqbal $Y$, Khan QA, Zia S, Malik A. Frequency and characteristics of ocular trauma in Gilgit, Pakistan. J Islam Int Med Coll. 2016;11(4):157-62

38. Wong TY, Tielsch JM. A population-based study on the incidence of severe ocular trauma in Singapore. Am J Ophthalmol. 1999;128(3):345-51. https://doi.org/10.1016/ s0002-9394(99)00167-1

PMid:10511030

39. Alem KD, Arega DD, Weldegiorgis ST, Agaje BG, Tigneh EG. Profile of ocular trauma in patients presenting to the department of ophthalmology at Hawassa University: Retrospective study. PLoS One. 2019;14(3):e0213893. https://doi.org/10.1371/ journal.pone.0213893

PMid:30921358 